\title{
A possible relationship between the anti-cancer potency of photodynamic therapy using the novel photosensitizer ATX-s10-Na(II) and expression of the vascular endothelial growth factor in vivo
}

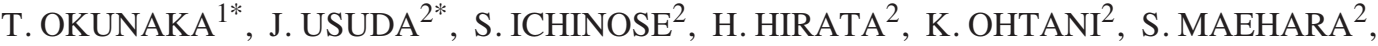

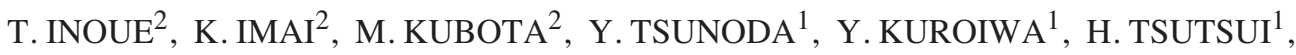 \\ K. FURUKAWA ${ }^{3}$, K. NISHIO ${ }^{4}$ and H. KATO ${ }^{2}$
}

\begin{abstract}
${ }^{1}$ Respiratory Disease Center, Sanno Hospital, International University of Health and Welfare; ${ }^{2}$ Department of Thoracic Surgery, Tokyo Medical University Hospital, Tokyo; ${ }^{3}$ Department of Thoracic Surgery, Tokyo Medical University Kasumigaura Hospital, Ibaraki; ${ }^{4}$ Pharmacology Division, National Cancer Center Research Institute, Tokyo, Japan
\end{abstract}

Received January 31, 2007; Accepted April 10, 2007

\begin{abstract}
ATX-s10-Na(II) is a novel second-generation photo-sensitizer for photodynamic therapy (PDT). PDT using ATX-s10 and diode laser $(670 \mathrm{~nm})$ induces an apoptotic response, inflammatory reaction, immune reaction and damage to the microvasculature. In particular, the vascular shut-down effect plays an important role in the anti-tumor activity of ATX-s10-PDT. It has been reported that PDT induces hypoxia and expression of the vascular endothelial growth factor (VEGF) via the hypoxia-inducible factor 1 (HIF1)- $\alpha$ pathway. We hypothesized that the expression of VEGF may cause tumor recurrence after PDT and exert unfavorable effect against the anti-tumor activity of ATX-s10PDT. In this study, we showed by DNA microarray analysis in vitro that VEGF mRNA expression was induced $3 \mathrm{~h}$ after laser irradiation in ATX-s10-PDT. We compared the antitumor activity of ATX-s10-PDT against lung cancer cell lines SBC-3 and SBC-3/VEGF, the latter overexpressing VEGF; there was no significant difference in the sensitivity to the PDT between the two cell lines as assessed by clonogenic assay. Furthermore, no statistically significant difference in the anti-tumor effect of PDT, as measured by tumor cures, was found between SBC-3 and SBC-3/VEGF tumors in female Balb/c-nu/nu nude mice in vivo. In conclusion, ATXs10-PDT may prevent tumor recurrence despite induction of VEGF and promotion of tumor angiogenesis, which are known to enhance tumor proliferation and survival.
\end{abstract}

Correspondence to: Dr Jitsuo Usuda, Department of Thoracic Surgery, Tokyo Medical University, 6-7-1, Nishishinjuku, Shinjuku-ku, Tokyo 160-0023, Japan

E-mail: jusuda@tokyo-med.ac.jp

${ }^{*}$ Contributed equally

Key words: photodynamic therapy, photosensitizer, vascular endothelial growth factor

\section{Introduction}

Photodynamic therapy (PDT), one of the treatment modalities for cancer, uses a photosensitizer and laser irradiation to induce the production of reactive oxygen species in cancer cells (1-4). In Japan, the US, and many other countries, PDT is widely used as a treatment option for solid cancers $(5,6)$. Since the first modern clinical trial of PDT reported in 1978 by Dougherty et al (7), PDT using photosensitizer, Photofrin (porfimer sodium), has been applied to many cancer types and is approved by the US Food and Drug Administration for the treatment of advanced esophageal cancer as well as early-stage and advanced-stage lung cancers $(8,9)$. In order to enhance the efficacy of PDT and expand its clinical applications, a variety of second-generation photosensitizers are now being assessed for their efficacy in cancer therapy $(4,10,11)$.

ATX-s10 is a second generation photosensitizer containing hydrophilic chlorine with a maximum absorption at $670 \mathrm{~nm}$, which can penetrate deeper than Photofrin, which has a maximum absorption wavelength of $630 \mathrm{~nm}$ (12-14). It has been reported that PDT using ATX-s10 and a diode laser has a strong anti-tumor effect and induces congestion and thrombus formation in tumor vessels, with degeneration of the tumor vascular endothelial cells $(12,13)$. Masumoto et al reported that in particular, a vascular shut-down effect plays an important role in the anti-tumor activity of PDT using ATX-s10 (14). Recently, we have reported that lysosomal damage by PDT using ATX-s10 can initiate apoptotic response and this apoptotic pathway can be regulated by photodamage to $\mathrm{Bcl}-2$ via mitochondrial damage (15). However, the precise mechanism of the anti-tumor effect of ATX-s10-PDT has not yet been elucidated.

Most photosensitizers, such as Photofrin, ATX-s10, phthalocyanine 4 ( $\mathrm{Pc} 4$ ), preferentially bind to mitochondrial membranes, endoplasmic reticulum, and Golgi complexes in cancer cells, but do not accumulate in cell nuclei $(2,3,15)$. It has been reported that PDT rapidly induce apoptosis, inflammatory reaction, tumor-specific and/or -nonspecific 
immune reaction and damages the microvasculature of the tumor bed (16-18). Sitnik et al have reported that microvasculature damage is readily observed histologically following PDT and leads to a significant decrease in blood flow as well as severe tissue hypoxia (19). Ferrario et al reported that reduction in vascular perfusion associated with PDT-mediated microvascular injury produced tumor tissue hypoxia, which induces vascular endothelial growth factor (VEGF) expression via activation of the hypoxia-inducible factor-1 (HIF-1) trans-cription factor (20).

In this study, in order to elucidate the precise mechanism of action of ATX-s10-PDT, we examined whether the increase of expression of VEGF caused by ATX-s10 via microvasculature damage could lead to recurrence, using VEGF secreting lung cancer in vivo.

\section{Materials and methods}

Cell culture. Human lung cancer cell line, SBC-3 was established at Department of Medicine, Okayama University school of Medicine (Okayama, Japan). SBC-3/VEGF cells were established at Pharmacology Division, National Cancer Center Research Institute $(21,22)$. SBC-3 cells and SBC-3/ VEGF cells were cultured in RPMI-1640 containing $10 \%$ fetal bovine serum at $37^{\circ} \mathrm{C}$ in humidified air containing $5 \% \mathrm{CO}_{2}$.

Mice. Female Balb/c-nu/nu nude mice, 5 weeks old were purchased from Japan Charles River Co., Ltd. (Atsugi, Japan) $(21,22)$. These mice were maintained under specific pathogenfree conditions in our university animal facility.

cDNA microarray analysis. Gene expressions in lung cancer cells, SBC-3 cells before PDT or $3 \mathrm{~h}$ after PDT, were analyzed using a cDNA microarray. We performed PDT for SBC-3 cells at $\mathrm{LD}_{90}\left(8.0 \mu \mathrm{g} / \mathrm{ml}\right.$ ATX-s $10,10 \mathrm{~J} / \mathrm{cm}^{2}$ laser irradiation $)$ dose and extract mRNA and purified using total RNA kit (Qiagen, Hilden, Gemany). RNA was reverse-transcribed in the presence of $\left[\alpha-{ }^{32}\right.$ p $]$ dATP using the Atlas Pure Total RNA labeling system (Clontech, Palo Alto, CA, USA). We used a commercially available cDNA microarray, the Atlas Human 1.2 array (Clontech), on which 1176 cancer-related gene fragments had been arrayed. Information about genes on the microarray can be obtained from URL; http://atlas.info. clontech.com. Hybridization of the ${ }^{32} \mathrm{p}$-labeled cDNA with the array with the array membrane was performed according to the manufacturer's instructions. The membrane was analyzed by an imaging analyzer (BAS2000; Fuji Photo Film, Tokyo, Japan) and the hybridization signals were quantified by the ArrayGauge version 1.2 software. Gene expression was quantified as the tumor-to-normal fluorescence ration ( $\mathrm{T}: \mathrm{N}$ ratio) $(23,24)$. The gene was overexpressed at $\geq 2$ and underexpressed when the ration was $<0.5$.

Photosensitizer. ATX-s10Na (II) (13,17-bis-1 carboxypropionyll carba-Moylethyl-8-e-thenyl-2-hydroxy-3-hydroxyimino-ethylidene-2,7,12,18-tetramethyl porphyrin sodium; molecular weight, 927.79) was supplied by the Photochemical Co. Ltd. (Okayama, Japan) (12-15). This photosensitizer has the highest absorption peak at $670 \mathrm{~nm}(12-15)$. ATX-s10 was stored as powder in the dark. The ATX-s10 powder was

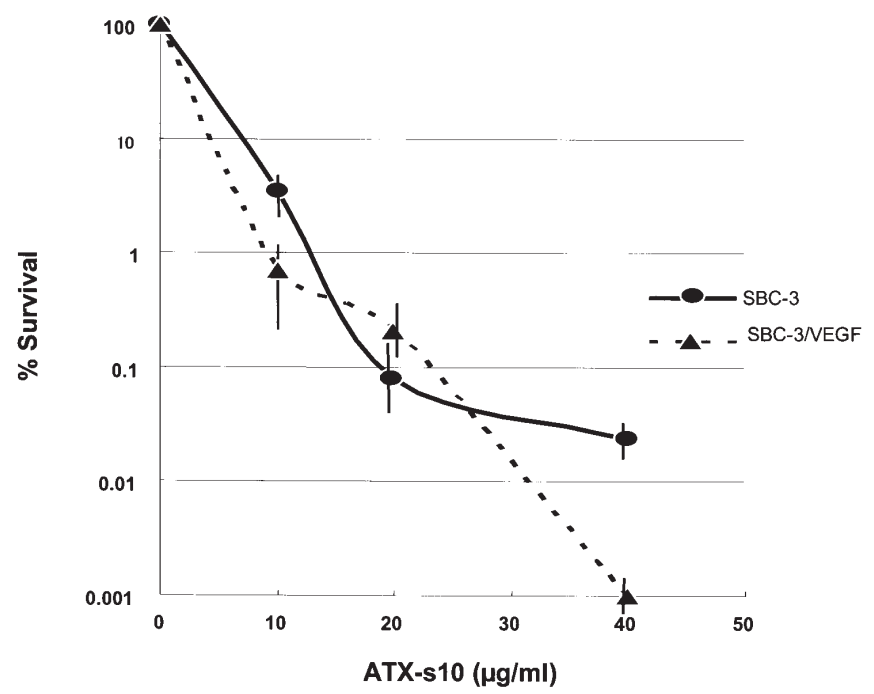

Figure 1. Loss of clonogenicity of SBC-3 cells and SBC-3/VEGF cells as a result of ATX-s10-PDT. Exponentially growing cultures of each cell line were treated with $10,20,40 \mu \mathrm{g} / \mathrm{ml} \mathrm{ATX}-\mathrm{s} 10$ for $3 \mathrm{~h}$, and then irradiated with 670-nm laser light at the dose of $10 \mathrm{~J} / \mathrm{cm}^{2}$. Immediately after the PDT, the cells were trypsinized, collected, diluted, and plated. The data from the PDT-treated cells were normalized to the plating efficiency of untreated cells of the same cell line. Each datum is the mean \pm standard deviation of the results from three indepedent experiments.

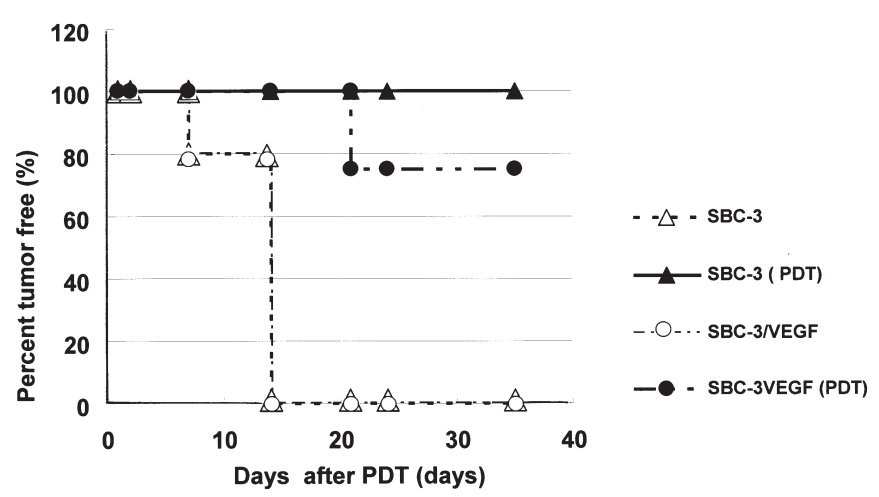

Figure 2. Mice transplanted with SBC-3 or SBC-3/VEGF tumors measuring 5-7 $\mathrm{mm}$ in diameter were treated by ATX-s10-PDT $(5 \mathrm{mg} / \mathrm{kg}$, iv) and laser irradiation $\left(200 \mathrm{~J} / \mathrm{cm}^{2}\right)$. Tumor response was monitored over a 35 -day evaluation period. The tumor volume was calculated using the following formula; $\mathrm{V}=\mathrm{LD}^{2} / 2 \mathrm{~L}$, the longest diameter; $\mathrm{D}$, the shortest diameter. Tumor volumes $>1000 \mathrm{~mm}^{3}$ were recorded as recurrence. In the SBC-3/VEGF tumors, 35 days after ATX-s10-PDT, tumor volume was $>1000 \mathrm{~mm}^{3}$. SBC-3 cells without treatment (triangles) and SBC-3 treated by PDT (solid triangles), SBC-3/VEGF cells without treatment (cicle), SBC-3/VEGF treated with PDT (solid dots).

dissolved in phosphate-buffered saline (PBS) (Invitrogen, CA, USA).

Laser unit. A diode laser (LD670-05; Hamamatsu Photonics K.K., Hamamatsu, Japan) emitting continuous-wave laser light at a wavelength of $670 \mathrm{~nm}$ was the light source for excitation of ATX-s10 (12-15).

Clonogenic cell survival. Cells were collected from the monolayer with trypsin immediately after ATX-s10-PDT. Aliquots 
Table I. Gene expression in SBC-3 cells following ATX-s10-PDT.

\begin{tabular}{|c|c|c|c|}
\hline Gene & GenBank \# & Up & Down \\
\hline c-jun proto-oncogene; transcription factor AP-1 & J04111 & 9.2 & \\
\hline $\begin{array}{l}\text { Mothers against dpp homolog } 4 \text { (SMAD4); MADR4; } \\
\text { pancreatic carcinoma gene } 4 \text { (DPC4) }\end{array}$ & U44378 & 6.2 & \\
\hline CDK-interacting protein 1 (CIP1); WAF1 & L25610 & 2.1 & \\
\hline Fos-related antigen (FRA1) & X16707 & 2.9 & \\
\hline CDC-like kinase 1 (CLK1) & L29222 & 4.6 & \\
\hline Growth arrest and DNA-damage-inducible protein 153 (GADD153) & S40706 & 7.9 & \\
\hline Growth arrest and DNA-damage-inducible protein (GADD45) & M60974 & 4.3 & \\
\hline DNA-binding protein CPBP & U44975 & 2.3 & \\
\hline $\begin{array}{l}\text { Integrin } \alpha \text { E precursor (ITGAE); mucosal lymphocyte- } 1 \text { antigen; } \\
\text { hml-1 antigen; CD103 antigen }\end{array}$ & L25851 & 3.2 & \\
\hline Macrophage inhibitory cytokine 1 (MIC1) & AF019770 & 2.6 & \\
\hline Early growth response $\alpha(\mathrm{EGR} \alpha)$ & S81439 & 2.4 & \\
\hline Proto-oncogene tyrosine-protein kinase abl; p150; c-abl & M14752 & & 2.1 \\
\hline $\begin{array}{l}\text { Met proto-oncogene; hepatocyte growth factor receptor precursor } \\
\text { (HGF-SF receptor) }\end{array}$ & J02958 & & 2.1 \\
\hline Epidermal growth factor receptor (EGFR) & X00588 & & 2.5 \\
\hline $\begin{array}{l}\text { Insulin-like growth factor binding protein } 4 \text { precursor (IGF-binding protein } 4 \text {; } \\
\text { IGFBP4; IBP4) }\end{array}$ & M62403 & & 2.8 \\
\hline $\begin{array}{l}\text { Tumor necrosis factor receptor } 1 \text { (TNFR1); tumor necrosis factor binding } \\
\text { protein } 1(\mathrm{TBP} 1) \text {; CD120A antigen }\end{array}$ & M33294 & & 2.4 \\
\hline Endothelial tumor necrosis factor $\alpha$-induced protein 1 ; B12 protein & M80783 & & 2.3 \\
\hline Integrin $\alpha 3$ (ITGA3); galactoprotein B3 (GAPB3); VLA3 $\alpha$ subunit; CD49C antigen & M59911 & & 2.1 \\
\hline integrin 34 (ITGB4); CD104 antigen & X53587 & & 2.2 \\
\hline High mobility group protein (HMG-I) & M23619 & & 2.1 \\
\hline $\begin{array}{l}\text { Lymphotoxin } ß \text { receptor precursor; tumor necrosis factor receptor } \\
\text { 2-related protein; tumor necrosis factor } \mathrm{C} \text { receptor }\end{array}$ & L04270 & & 2.3 \\
\hline Fibroblast growth factor receptor 4 (FGFR4) & L03840 & & 2.1 \\
\hline CD9 antigen; p24; leukocyte antigen MIC3 & M38690 & & 2.8 \\
\hline Laminin $\gamma 1$ subunit precursor (LAMC1); laminin B2 subunit (LAMB2) & J03202 & & 2.5 \\
\hline
\end{tabular}

of the cells were seeded into $25 \mathrm{~cm}^{2}$ flasks in amounts sufficient to yield 50-150 colonies. After incubation for 10-14 days, the cells were stained with $0.1 \%$ crystal violet in $20 \%$ ethanol, and colonies containing at least 50 cells were counted $(15,25)$. The plating efficiency of untreated cells was $30-40 \%$.

In vivo treatment protocols. SBC-3 cells and SBC-3/VEGF cells were harvested during the exponential growth phase.
Cells were washed twice in Hank's solution (Invitrogen) and $10^{7}$ cells were inoculated subcutaneously into the right thigh of nude mice (19-21). The lesions reached 6-7 $\mathrm{mm}$ in diameter and then the transplanted tumors were treated by ATX-s10PDT. Three hours after ATX-x10 (5 mg/kg) was intravenously administered; the tumors were irradiated by $200 \mathrm{~J} / \mathrm{cm}^{2}$ dose of 670-nm light. After ATX-s10-PDT, mice were monitored for tumor recurrences 3 times per week for 24 days. Tumor volumes were calculated using the following formula: Tumor 
volume $=\mathrm{LD}^{2} / 2(\mathrm{~L}$, long diameter; $\mathrm{D}$, short diameter $)$. Tumor volumes $>1000 \mathrm{~mm}^{3}$ were recorded and judged as recurrence (19-21,26).

\section{Results and Discussion}

Using a microarray analysis 11 overexpressed genes ( $\mathrm{T}: \mathrm{N}$ ratio $>2.0$ ) and 13 underexpressed genes were identified following ATX-s10-PDT at $\mathrm{LD}_{90}$ dose $\left(8 \mu \mathrm{g} / \mathrm{ml}\right.$ ATX-s $10,10 \mathrm{~J} / \mathrm{cm}^{2}$ laser irradiation). In cell cycle related genes, mRNA of SMAD4, p2 $1^{\mathrm{CIP} 1}$, CDC-like kinase (CLK-1) genes were induced $3 \mathrm{~h}$ after PDT (Table I). In particular, the induction of $\mathrm{p} 21^{\mathrm{CIP} 1}$ can be an important factor as an apoptotic response as we previously reported that ATX-s10-PDT caused morphologically typical apoptosis (15). Although photosensitizer ATX-s10 does not accumulate in cell nuclei and the potential of PDT to cause DNA damage, mutations, and carcinogenesis is low, Table I shows that DNA damage-inducible genes (GADD-153, GADD-45) were highly overexpressed after PDT. GADD-153 (CHOP) was originally identified as a growth arrest and DNA damage-inducible gene (27), and Wong et al reported that it was identified as a highly overexpressed gene following Photofrin-PDT (28). GADD-153 is also an endoplasmic reticulum (ER) stress inducible transcription factor involved in the development of apoptosis. These data suggest that ATX-s10-PDT can damage ER membrane as we previously reported that ATX-s10 localized to mitochondria, lysosomal, ER and other intracellular organelles (15).

It has been reported that PDT rapidly induces inflammatory reaction, tumor-specific and/or -nonspecific immune reaction $(2,4,15,16,29)$. We previously reported that TNF- $\alpha$, IL-2, IL-6 were induced by NPe6-PDT (16). In this study, PDT using ATX-s10 induced VEGF, IL-6, and endothelial plasminogen activator inhibitor-1 (Table I). It is unclear whether the expression of VEGF may be a determinant factor of antitumor activity of ATX-s10-PDT in vitro. We evaluated the sensitivity of SBC-3/VEGF cells, which overexpress vascular endothelial growth factor, against ATX-s10-PDT by clonogenic assay (Fig. 1). The survival curves indicate that there was no significant difference of the anti-tumor effect between in SBC-3/VEGF and parent SBC-3 cells (Fig. 1). This result suggests that VEGF expression does not exert a marked regulatory effect on cell survival of ATX-s10-PDT in vitro. However, Masumoto et al reported that a vascular shut-down effect played an important role in the anti-tumor activity of ATX-s10-PDT (14). With some photosensitizers, the effect on the vasculature is the most important mechanism of the therapeutic effect by PDT. Gomer et al reported that PhotofrinPDT induced expression of HIF- $1 \alpha$ and VEGF in tumors (11), and that tumor-bearing mice treated with a combination of Photofrin-PDT and non-specific antiangiogenetic agents improved anti-tumor effect as measured by increased time to recurrence and increased cures $(11,20,26)$. We hypothesized that ATX-s10-PDT may attribute its failure as recurrence to the induction of expression of VEGF following the damage of microvasculature and hypoxic change in the tumors. Jiang et al demonstrated that by immunohistological study, VEGF expression increased within the PDT-treated lesion one week after Photofrin-PDT and remained elevated for a few weeks, and they suggested that tumor recurrence after PDT may be regulated by the enhancement of VEGF expression and angiogenesis within the treated area (30).

However, as Fig. 2 shows, there was no statistical difference of the anti-tumor effect as measured by tumor cures between SBC-3 tumors and SBC-3/VEGF tumors in vivo. These data suggest that ATX-s10-PDT has anti-tumor effect depending upon expression of VEGF and a unique tumoricidal action. In conclusion, ATX-s10-PDT may prevent tumor recurrence in spite of induction of VEGF and promotion of tumor angiogenesis, which are known to enhance tumor proliferation and survival.

\section{Acknowledgements}

This study was supported in part by a Grant-in-Aid for Young Scientists (B) from the Ministry of Education, Culture, Sports, Science and Technology, Japan (MEXT), KAKENHI 18791002 (to J.U.).

\section{References}

1. Dougherty TJ, Gomer CJ, Barbara WH, et al: Photodynamic therapy. J Natl Cancer Inst 90: 889-905, 1998.

2. Oleinick NL, Morris RL and Belichenko I: The role of apoptosis in response to photodynamic therapy: what, where, why, and how. Photochem Photobiol Sci 1: 1-21, 2001.

3. Usuda J, Kato H, Okunaka T, et al: Photodynamic therapy (PDT) for lung cancers. J Thorac Oncol 1: 489-493, 2006.

4. Kato H, Usuda J, Okunaka T, et al: Basic and clinical research on photodynamic therapy at Tokyo Medical University Hospital. Lasers Surg Med 38: 371-375, 2006.

5. Dougherty TJ: An update on photodynamic therapy applications. J Clin Laser Med Surg 20: 3-7, 2002.

6. Kato H, Furukawa K, Sato M, et al: Phase II clinical study of photodynamic therapy using mono-L-aspartyl chlorine e6 and diode laser for early superficial squamous cell carcinoma of the lung. Lung Cancer 42: 103-111, 2003.

7. Dougherty TJ, Lawrence G, Kaufman JH, et al: Photoradiation in the treatment of recurrent breast carcinoma. J Natl Cancer Inst 62: 231-237, 1979.

8. Loewen GM, Pandy R, Bellnier D, et al: Endobronchial photodynamic therapy for lung cancers. Lasers Surg Med 38: 364-370, 2006.

9. Mathur PN, Edell E, Sutedja T, et al: Treatment of early stage non-small cell lung cancer. Chest 123: 176-180, 2006.

10. Kamuhabwa AR, Huygens A, Roskams T, et al: Enhancing the photodynamic effect of hypericin in human bladder transitional cell carcinoma spheroids by the use of the oxygen carrier, perfluorodecalin. Int J Oncol 28: 775-780, 2006.

11. Gomer CJ, Ferrario A, Luna M, et al: Photodynamic therapy: Combined modality approaches targeting the tumor microenvironment. Lasers Surg Med 38: 516-521, 2006.

12. Mori M, Sakata I, Hirano T, et al: Photodynamic therapy for experimental tumors using ATX-s10 (Na), a hydrophilic chlorine for photosensitizer, and diode laser. Jpn J Cancer Res 91: 753-759, 2000.

13. Huang Y, Obana A, Gohto Y, et al: Comparative study of the phototoxicity of two chlorine type photosensitizer, ATX-s10 (Na) and Verteporfin, on vascular endothelial and retinal pigment epithelial cells. Lasers Surg Med 34: 2116-2226, 2004.

14. Masumoto K, Yamada I, Tanaka H, et al: Tissue distribution of a new photosensitizer ATX-s10 (Na) (II) and effect of a diode laser laser $(670 \mathrm{~nm})$ in photodynamic therapy. Lasers Surg Sci 18: 134-138, 2003.

15. Ichinose S, Usuda J, Hirata T, et al: Lysosomal cathepsin initiates apoptosis, which is regulated by photodamage to $\mathrm{Bcl}-2$ at mitochondria in photodynamic therapy using a novel photosensitizer, ATX-s10 (Na). Int J Oncol 29: 349-355, 2006.

16. Usuda J, Okunaka T, Furukawa K, et al: Increased cytotoxic effects of photodynamic therapy in IL-6 gene transfected via enhanced apoptosis. Int J Cancer 93: 475-480, 2001. 
17. Chen B, Pogue BW, Zhou X, et al: Effect of tumor host microenvironment on photodynamic therapy in a rat prostate tumor model. Clin Cancer Res 11: 720-727, 2005.

18. Huang Z, Chen Q, Luck D, et al: Studies of a vascular-acting photosensitizer, Pd-Bacteriopheophorbide (Tookad), normal canine prostate and spontaneous canine prostate cancer. Lasers Surg Med 36: 390-397, 2005.

19. Sitnik TM, Hampton JA, Henderson BW, et al: Reduction of tumor oxygenation during and after photodynamic therapy in vivo: effect of fluence rate. Br J Cancer 77: 1386-1394, 1998.

20. Ferrario A, von Tiehl KF, Rucker N, et al: Antiangiogenic treatment enhances photodynamic therapy responsiveness in a mouse mammary carcinoma. Cancer Res 60: 4066-4069, 2000.

21. Natsume T, Watanabe J, Koh Y, et al: Antitumor activity of TZT-1027 (Soblidotin) against vascular endothelial growth factor-secreting human lung cancer in vivo. Cancer Sci 94: 826-833, 2003.

22. Koizumi F, Kitagawa M, Negishi T, et al: Novel SN-38incorporating polymeric micelles, NK012, eradicate vascular endothelial growth factor-secreting bulky tumors. Cancer Res 66: 100048-100056, 2006.

23. Nakamura $\mathrm{H}$, Saji $\mathrm{H}$, Ogata A, et al: cDNA microarray analysis of gene expression in pathologic stage IA non-small cell lung cancer. Cancer 97: 2798-2805, 2003.
24. Natsume T, Koh Y, Kobayashi M, et al: Enhanced antitumor activities of TZT-1027 against TNF-alpha or IL-6 secreting Lewis lung carcinoma in vivo. Cancer Chemother Pharmacol 49: $33-47,2002$

25. Usuda J, Azizuddin K, Chiu SM, et al: Association between the photodynamic loss of $\mathrm{Bcl}-2$ and the sensitivity to apoptosis caused by phthalocyanine photodynamic therapy. Photochem Photobiol 78: 1-8, 2003.

26. Ferrario A, Chantrain CF, von Tiehl Karl, et al: The matrix metalloproteinase inhibitor prinomastat enhances photodynamic therapy responsiveness in a mouse tumor model. Cancer Res 64: 2328-2332, 2004

27. Oyadomori S and Mori M: Roles of CHOP/GADD153 in endoplasmic reticulum stress. Cell Death Differ 11: 381-389, 2004.

28. Wong S, Luna M, Ferrario A, et al: CHOP activation by photodynamic therapy increases treatment induced photosensitization. Lasers Surg Med 35: 336-341, 2004.

29. Gollnick SO, Liu X, Owczarzak B, et al: Altered expression of interleukin 6 and interleukin 10 as a result of photodynamic therapy in vivo. Cancer Res 57: 3904-3909, 1997.

30. Jiang F, Zhang ZG, Katakowski M, et al: Angiogenesis induced by photodynamic therapy in normal rat brain. Photochem Photobiol 79: 494-498, 2004. 